EPiC Series in Engineering
Volume 3, 2018, Pages 1316-1323
HIC 2018. 13th International
Conference on Hydroinformatics

\title{
Robust Reliability Assessment of Water Reservoir Under Uncertainty of Climate Change
}

\author{
Daniel Marton $^{1 *}$ and Kateřina Knoppová ${ }^{1,2}$ \\ ${ }^{1}$ Brno University of Technology, Faculty of Civil Engineering, Institute of Landscape Water \\ Management, Brno 602 00, Czech Republic. \\ ${ }^{2}$ Czech Hydrometeorological Institute, Regional Office Brno, Kroftova 2578/43, 61667 Brno, \\ Czech Republic. \\ marton.d@fce.vutbr.cz, knoppova.k@fce.vutbr.cz
}

\begin{abstract}
The aim of this paper is to introduce method of the robust reservoir performance evaluation under the climate change uncertainty. Water resources adaptation on climate change, drought management strategies as well as hydrological and reservoir modeling in the climate change uncertainty have been serious issues. Newly developed lumped water balance model and reservoir simulation model will be used. Based on these tools the approach of robust reservoir storage capacity reliability assessment will be introduced. The hydrological data under climate change will be constructed using the statistical downscaling tool LARS WG. Ensemble of 29 climate scenarios will be created. The hydrology analysis and the temporal reliability of reservoir storage capacity and its robustness assessment against the climate change uncertainty will be presented on the case study of the Vir I reservoir and Svratka river basin in the Czech Republic.
\end{abstract}

\section{Introduction}

The climate change represents a very serious topic and it has been discussed in academic, social and technical context. Hydrological extremes have been appearing increasingly in the Czech Republic and the fact even reinforces the discussion on the climate change issue. On one hand, Czech Republic has suffered severe flooding (years 1997, 2002, 2006, 2009 and further), on the other hand, there have been extreme droughts. Weather events that have appeared since 2012 only confirm the trend. The years 2011 and 2012 were evaluated as years with very low river flows (Zahradníček, et al., 2014); while in the spring 2013, some parts of the Czech landscape were flooded during three flood episodes. In the winter of 2013/2014, air temperatures were higher than long term averages; the snow cover height was very low and reached a 20 -year minimum. Recently year 2015 was also extreme regarding the meteorological measurement, even on the global scale. It broke records also in the Czech 
Republic: according to the Czech Hydrometeorological Institute (CHMI), mean annual air temperature reached $9.4^{\circ} \mathrm{C}$, which is $1.9^{\circ} \mathrm{C}$ higher than the long-term average value. The total annual precipitation also reached the record level, only $532 \mathrm{~mm}$ which represents the decrease of $21 \%$ compared to the long-term average (Ministry of Agriculture of the Czech Republic, 2018). World Meteorological Organization announced the years 2015, 2016 and 2017 as the warmest years registered in the history of measurements. Lately, we can more often observe a trend of erasing the differences between seasons, which is typical for the temperate climate zone of the Czech Republic. The number of the winter days is declining and the transition between winter and spring is slowly dissipating. Gradual transformation of natural climatic, vegetational and hydrological cycles could be the consequence of these changes. It has been estimated that mean long-term river flows could drop of $20-40 \%$ on Czech Republic due to climate changes (Kašpárek, Peláková, \& Boersema, 2005). An expected redistribution of precipitation within the year and consequential hydrological cycle changes would be the cause of this phenomenon.

The Czech Government, Ministry of Agriculture and Ministry of Environment including the River Basin Managers, began to react to the state induced by the lack of water in the catchments. Feasibility studies for water reservoirs in the endangered regions were ordered and performed. Current reservoir capacities are recalculated and the possibilities of water transfers to potentially threatened river basins are considered. Water resources adaptation on climate change, drought management strategies as well as hydrological and reservoir modelling in the climate change uncertainty are becoming crucial issues.

However, the development of products and methods needed for climate change analysing targeted to water reservoir analysis is limited. Worldwide, a range of hydrological models used for climate change analysis of catchment hydrology and water resource management exist. The well - known models are, for example, HEC - HMS (Scharffenberg \& Fleming, 2008), TOPMODEL, Soil and Water Assessment Tool (SWAT), HBV - 96, MIKESHE (Devia, Ganasri, \& Dwarakish, 2015) or Czech model BILAN (Vizina, Horáček, \& Hanel, 2015). Their disadvantage is a certain degree of complexity, catchment scale limits, open source limitations and etc., as well as integration with other external applications. The aim of this paper is to introduce lumped water balance model as well as reservoir simulation model suitable for robust reservoir performance assessment under climate change uncertainty. Hydrological data under climate change are construct based on statistical downscaling using LARS WG software. An ensemble of maximum 29 climate scenarios was created and the analysis of temporal reliability of reservoir storage capacity will be presented. Climate change uncertainties have been evaluated by the robustness of given temporal reliability of storage capacity. To illustrate the functions of the models the Svratka river basin and Vir I reservoir in Vysocina Region, in the central part of the Czech Republic have been studied. The main contributions of presented paper are: The new hydrological model was formed and connected to the reservoir simulation model, which is able to compute with data ensemble describing a climate change uncertainty. The water balance equations applied in (Wang, et al., 2013) on a large arid basin in China were modified for different hydrological conditions of Central Europe. Also, the method of robustness evaluation described in (Paton, Maier, \& Dandy, 2014) and (Roach, Kapelan, Ledbetter, \& Ledbetter, 2016) was used to find an optimal temporal reliability assessment of reservoir storage capacity under climate change uncertainty conditions.

\section{Methodology}

Lumped water balance model as hydrological modelling tool is the basis of the paper. The hydrological model is based on the formulas described by (Wang, et al., 2013). These main rainfallrunoff equations are described as follows: 


$$
q_{s, i}=k_{s} \cdot \frac{S_{i-1}}{S_{\max }} \cdot h_{s, i}
$$

where $\mathrm{q}_{\mathrm{s}, \mathrm{i}}$ is the mean monthly surface flow $[\mathrm{mm}]$ for $\mathrm{i}=1, \ldots, \mathrm{n}, \mathrm{k}_{\mathrm{s}}$ is the coefficient of surface flow [-]. $\mathrm{S}_{\mathrm{i}-1}$ is mean soil moisture in i-1 time step [mm], $\mathrm{S}_{\max }$ is the maximum soil moisture storage $[\mathrm{mm}], \mathrm{h}_{\mathrm{s}, \mathrm{i}}$ is total monthly precipitation $[\mathrm{mm}] \mathrm{i}=1, \ldots, \mathrm{n}$. Equation (2) describes the groundwater flow $\mathrm{q}_{\mathrm{g}, \mathrm{i}}$ :

$$
q_{g, i}=k_{g} \cdot S_{i-1}
$$

where $\mathrm{q}_{\mathrm{g}, \mathrm{i}}$ is the mean monthly groundwater discharge $[\mathrm{mm}], \mathrm{kg}$ is the coefficient of groundwater flow [-] and $\mathrm{S}_{\mathrm{i}-1}$ is the mean soil moisture in i-1 time step [mm]. In the next step the monthly evaporation $E_{i}$ is evaluated using Equation (3):

$$
\mathrm{E}_{\mathrm{i}}=\mathrm{k}_{\mathrm{e}} \cdot \frac{\mathrm{S}_{\mathrm{i}-1}}{\mathrm{~S}_{\max }} \cdot \mathrm{E}_{\mathrm{P}, \mathrm{i}}
$$

where $E_{i}$ is the mean monthly evaporation from the basin in i time step $[\mathrm{mm}]$ for $i=1, \ldots, n, k_{e}$ is the coefficient of estimated evaporation [-], $\mathrm{E}_{\mathrm{p}, \mathrm{i}}$ is the potential monthly evaporation [mm], calculated by Thornthwaite method. Finally, the total runoff $\mathrm{q}_{c, i}$ from the basin is estimated according to (4):

$$
q_{c, i}=q_{s, i}+q_{g, i}
$$

where $\mathrm{q}_{c, i}$ is the total discharge from the basin per month $\mathrm{i}[\mathrm{mm}]$ for $\mathrm{i}=1, \ldots, \mathrm{n}$. The soil moisture content $\mathrm{S}_{\mathrm{i}}$ is estimated using (5):

$$
S_{i}=S_{i-1}+h_{s, i}-q_{c, i}-E_{i}
$$

where $\mathrm{S}_{\mathrm{i}}$ is the soil moisture at the end of month $\mathrm{i}[\mathrm{mm}]$ for $\mathrm{i}=1, \ldots, \mathrm{n} . \mathrm{S}_{\mathrm{i}-1}$ is the mean soil moisture in i-1 time step $[\mathrm{mm}], \mathrm{h}_{\mathrm{s}, \mathrm{i}}$ is the total monthly precipitation $[\mathrm{mm}]$ in time step $\mathrm{i}=1, \ldots, \mathrm{n}, \mathrm{q}_{\mathrm{c}} \mathrm{i}$ is the total discharge from the basin $[\mathrm{mm}] \mathrm{i}=1, \ldots, n$. $\mathrm{E}_{\mathrm{i}}$ is the mean monthly evaporation from the basin in $\mathrm{i}$ time step $[\mathrm{mm}] \mathrm{i}=1, \ldots, \mathrm{n}$. In all used formulas, $\mathrm{n}$ is the total number of months in the time series.

37 parameters in the control equations had to be calibrated. The parameters are: 12 coefficients of monthly surface flow, 12 coefficients of monthly groundwater flow, 12 coefficients of monthly evapotranspiration and 1 parameter of initial surface soil moisture. These 37 coefficients were decision variables for model optimization. The Objective function was to maximize Nash-Sutcliffe model efficiency coefficient (NSE). The gradient optimization method was applied to solve the optimization problem.

A calibrated and validated hydrological model was used for creating the hydrological data under climate change. The downscaled climatological datasets representing climate change scenarios of the studied river basin were put into the model. Statistical downscaling was made using the LARS WG software (Semenov, Pilkington-Bennet, \& Calanca, 2013), (Racsko, Szeidl, \& Semenov, 1991). The ensemble of 29 future scenarios was created.

A reservoir simulation model was developed based on the mass balance equation described in (Marton, Starý, \& Menš́k, 2015), (Marton, Paseka, \& Knoppová, 2016). General reliability of the water management system were described by (Hashimoto, Stedinder, \& Loucks, 1982). During simulation the temporal reliability $\mathrm{R}_{\mathrm{T}}$ was evaluated used definition by (Klemes, 1967). 
After reliability assessment of all hydrological time series, the robustness (ROB) of given reliability assessment of reservoir storage capacity was calculated. In this case the robustness could be considered as statistical evaluation of uncertain results under the uncertainty of climate change. Robustness was calculated according (7) and is based on (Paton, Maier, \& Dandy, 2014), (Roach, Kapelan, Ledbetter, \& Ledbetter, 2016),

$$
R O B=\frac{1}{N} \sum_{j=1}^{N} S_{j}
$$

where ROB is robustness, $\mathrm{Sj}$ is the system evaluation of boundary conditions loaded by uncertainty for $\mathrm{j}=1, \ldots, \mathrm{N} . \mathrm{j}$ is the number of input hydrological time series created by the input ensemble. The resulting value 1 means satisfactory evaluation while 0 stands for an unsatisfactory evaluation. System evaluation is defined as (8):

$$
S_{j}=\left\{\begin{array}{l}
1, R_{T, j} \geq R_{T}, \text { for } j=1, \ldots, N \\
0, R_{T, j}<R_{T}, \text { for } j=1, \ldots, N
\end{array}\right.
$$

where $\mathrm{R}_{T, j}$ is the temporal reliability for $\mathrm{j}=1, \ldots, \mathrm{N}$ solutions and $\mathrm{R}_{\mathrm{T}}$ is the required temporal reliability.

\section{Case study}

For practical application the Vir I reservoir and the Svratka river basin have been chosen for many reasons. The location of Vir I reservoir is located in the central part of the Czech Republic, approximately $150 \mathrm{~km}$ south east of the capital city Prague. The reservoir is one of the main surface water resources in the South Moravia region. The basin and reservoir are covered by a long period of climatological and hydrological measurement, but a climate change analysis has never been made on this reservoir. It is known that the whole region is under hydrological stress caused by recent drought episodes. The reservoir volume serves mainly as the flood protections capacity, water supply capacity and capacity for the hydropower production.

The Svratka river is the main water inflow into the reservoir. The mean long-term inflow into the reservoir $Q_{a}$ is $3.34 \mathrm{~m}^{3} \mathrm{~s}^{-1}$. The mean annual value of evaporation from the water surface EANNUAL is $700 \mathrm{~mm}$. The total reservoir volume $\mathrm{V}_{\text {tотаL }}$ is $56.193 \mathrm{mil} \mathrm{m}^{3}$, the active storage volume $\mathrm{V} Z$,max $_{\text {is }}$ $44.056 \mathrm{mil} \mathrm{m}^{3}$ and the flood reservoir volume $\mathrm{V}_{\mathrm{FLOOD}}$ is $8.337 \mathrm{mil} \mathrm{m}^{3}$. The total outflow Op consists of the ecological flow OECO and the water withdrawal for water supply Ows (drinking water and industry). The total outflow Op is $2.53 \mathrm{~m}^{3} \mathrm{~s}^{-1}$, is divided to $\mathrm{OECO}=0.53 \mathrm{~m}^{3} \mathrm{~s}^{-1}$ and $\mathrm{Ows}_{\mathrm{ws}}=2 \mathrm{~m}^{3} \mathrm{~s}^{-1}$. The temporal reliability of reservoir storage capacity $\mathrm{R}_{\mathrm{T}}$ estimated by reservoir managers is $99.5 \%$.

The area of the Svratka catchment upstream the reservoir is $366.94 \mathrm{~km}^{2}$. The climatological data is measured at the climatological stations Policka and Svratouch by CHMI. The climatological observation covers daily air temperatures and daily precipitations. The hydrological data is in a form of mean monthly flows. The length of the time series is 1964-2016. Measurement is provided in the hydrometric profile Dalecin located on the river near to main tributary to reservoir. These stations are located in the catchment upstream the reservoir, see Figure 1. Model calibration was made using the 40 years from 1964 to 2003 . The model validation was made for 13 years from 2004 to 2016. The calibration inputs were mean monthly air temperatures, precipitations and river flows.

The ensemble of climatic data describing the climate change and the climate models and emission scenarios uncertainties for three future time periods and their combinations has been created. The mean daily air temperature and daily precipitation data represent inputs into the downscaling tool. The 
adapted statistical characteristics data from 12 climate models for SRES emission scenarios A1B, A2 and B1 implemented in LARS WG software were the basis of the input data. The ensemble of 29 possible climate data scenarios containing mean daily temperature and daily precipitation were the outcome of the LARS WG. Then three time periods and their combinations were defined: P1 (20112030), P2 (2046-2065) and P3 (2080-2099). The combinations of P1+P2 periods (2011-2065) and $\mathrm{P} 1+\mathrm{P} 2+\mathrm{P} 3$ periods (2011-2099) were modeled as well. Prior to usage in the hydrological model, the ensemble was recalculated to monthly values, so that the time step was uniform for all the computations.

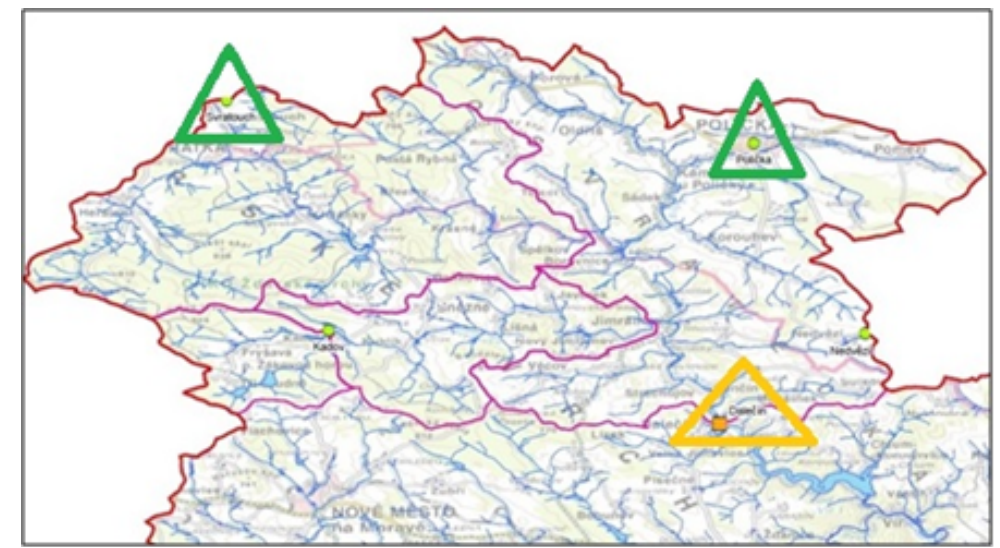

Figure 1. Location of the climatic and hydrometric stations in the Svratka river basin

\section{Results and discussion}

As first step, the calibration and validation of the hydrological model on the historical data time series was made. Resulting NSE for hydrological model calibration is 0.699. NSE for model validation is 0.6. The validation results of hydrological model are shown in Figure 2.

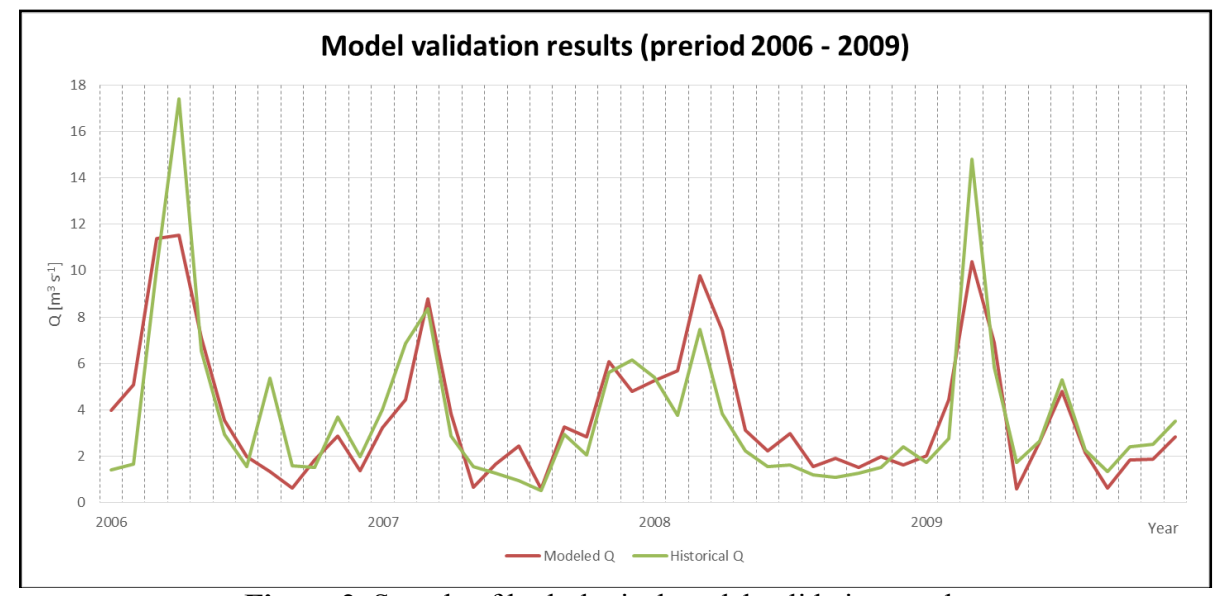

Figure 2. Sample of hydrological model validation results.

After that, the ensemble of climatic data representing the climate change was added into the model. The ensemble of hydrological data in the form of mean monthly inflow to the reservoir under 
climate change is the result of hydrological transformation. Before the reservoir simulation model was used, the hydrological analysis in the catchment upstream the reservoir had been accomplished. To ensure that the output data could be used and then compared with real values, a simplified BIAS correction of the hydrological data was applied. The ratio between BIAS data and the historical data was found and the ensemble of hydrological datasets was modified according to it. Subsequently the ensemble was divided into the groups A1B, B1 and A2 according to the SRES scenario and statistically evaluated. Mean values of the long-term mean flow $\mu\left(\mathrm{Q}_{\mathrm{a}}\right)$, minimal and maximal values $\min \left(\mathrm{Q}_{\mathrm{a}}\right)$ and $\max \left(\mathrm{Q}_{\mathrm{a}}\right)$ and the percent variance $\Delta \mathrm{Q}_{\mathrm{a}}$ have been determined for the $\mathrm{P} 1, \mathrm{P} 2, \mathrm{P} 3$ periods and then their combination $\mathrm{P} 1+\mathrm{P} 2+\mathrm{P} 3$. The results are compared to the real value of $\mathrm{Q}_{\mathrm{a}}$ in the Svratka river. Table 1 shows the results of the analysis.

\begin{tabular}{lcccc}
\hline Scenario (period) & $\mu\left(Q_{a}\right)\left[\mathrm{m}^{3} \mathrm{~s}^{-1}\right]$ & $\min \left(Q_{a}\right)\left[\mathrm{m}^{3} \mathrm{~s}^{-1}\right]$ & $\max \left(Q_{a}\right)\left[\mathrm{m}^{3} \mathrm{~s}^{-1}\right]$ & $\Delta Q_{a}[\%]$ \\
\hline Real Qa $(1950-2016)$ & 3.280 & - & - & - \\
P1 - A1B & 3.018 & 2.732 & 3.297 & -7.970 \\
P2 - A1B & 2.779 & 2.454 & 2.985 & -15.279 \\
P3 - A1B & 2.436 & 2.003 & 2.828 & -25.722 \\
P1+P2+P3 - A1B & 2.744 & 2.397 & 2.914 & -16.324 \\
P1 - A2 & 3.087 & 2.875 & 3.460 & -5.865 \\
P2 - A2 & 2.705 & 2.605 & 2.896 & -17.524 \\
P3 - A2 & 2.218 & 1.998 & 2.393 & -32.369 \\
P1+P2+P3 - A2 & 2.670 & 2.525 & 2.819 & -18.586 \\
P1 - B1 & 3.055 & 2.731 & 3.522 & -6.859 \\
P2 - B1 & 2.883 & 2.693 & 3.237 & -12.104 \\
P3 - B1 & 2.727 & 2.269 & 3.312 & -16.868 \\
P1+P2+P3 - B1 & 2.888 & 2.564 & 3.109 & -11.944 \\
\hline
\end{tabular}

Table 1: The results of hydrological analysis of the Svratka river basin upstream the Vir I Reservoir.

The last step of the computation is the analysis of the reservoir storage capacity in terms of the climate change uncertainties. The target of the analysis is to find the mean value of total outflow $\mu\left(\mathrm{O}_{\mathrm{P}}\right)$, which would fit the requested criterion $\min \left\{\mu\left(\mathrm{R}_{\mathrm{T}}\right)-\left(\mathrm{R}_{\mathrm{T}}=99,5 \%\right)\right\}$. When the optimal $\mu\left(\mathrm{O}_{\mathrm{P}}\right)$ was found, resulting $\mathrm{R}_{\mathrm{T}}$ set gained from the input data ensemble calculation was statistically evaluated. The Standard deviation $\sigma\left(\mathrm{R}_{\mathrm{T}}\right)$, intervals $\min \left(\mathrm{R}_{\mathrm{T}}\right)$ and $\max \left(\mathrm{R}_{\mathrm{T}}\right)$ were determined. Finally, the robustness ROB was evaluated for the optimal solution. ROB was computed for $\mathrm{R}_{\mathrm{T}}=99.5 \%$ temporal reliability limit, or the system was evaluated as satisfactory when $\mathrm{R}_{\mathrm{T}} \geq 99.5 \%$ and $\mathrm{VZ}, \max =44.056 \mathrm{mil} \mathrm{m}^{3}$. The results of reliability assessment and the results of robustness can be seen in Table 2 .

\begin{tabular}{lcccccc}
\hline Period & $\mu\left(O_{P}\right)\left[\mathrm{m}^{3} \mathrm{~s}^{-1}\right]$ & $\mu\left(R_{T}\right)[\%]$ & $\sigma\left(R_{T}\right)[\%]$ & $\min \left(R_{T}\right)[\%]$ & $\max \left(R_{T}\right)[\%]$ & $R O B$ \\
\hline P1 & 2.491 & 99.509 & 0.630 & 97.620 & 99.940 & 0.690 \\
P2 & 2.282 & 99.504 & 1.047 & 95.400 & 99.940 & 0.793 \\
P3 & 1.923 & 99.505 & 1.292 & 94.100 & 99.940 & 0.897 \\
P1+P2 & 2.362 & 99.502 & 0.859 & 96.130 & 99.970 & 0.759 \\
P1+P2+P3 & 2.035 & 99.503 & 1.139 & 95.410 & 99.980 & 0.862 \\
\hline
\end{tabular}

Table 2: The results of storage reliability assessment and robustness. 
As assumed, the results show that river flows in the basin will go down. In Table 1 we can see the decline about $8 \%$ in $\mathrm{P} 1$ period and $26 \%$ in $\mathrm{P} 3$ period for $\mathrm{A} 1 \mathrm{~B}$ emission scenario, which is considered as balanced. For the A2 scenario, so called pessimistic, a flow drop effect is in P1 to P3 between 6 and $32 \%$. Optimistic B1 scenario shows decreasing flow from 7 to $17 \%$ in $\mathrm{P} 1$ to $\mathrm{P} 3$ periods. It is obvious, that the long-term river flows will decline significantly in the future years according to used climate change scenarios. This fact will certainly influence the reservoir outflow. The mean value of total outflow will decrease of $1.54 \%$ with $\mathrm{ROB}=0.690$ in $\mathrm{P} 1$ period compared to the present value $\mathrm{O}_{\mathrm{P}}=2.53 \mathrm{~m}^{3} \mathrm{~s}^{-1}$. That means, that 20 out of 29 scenarios will satisfy the $\mathrm{R}_{\mathrm{T}}$ and $\mathrm{V}_{\mathrm{Z} \text {,max }}$ requirements. In P2 period, the reservoir outflow will decrease amount $9.8 \%$ with ROB value 0.793 . Consequently, 23 out of 29 scenarios will fulfil the water demands. In P3 period, the percent outflow decrease will be the largest and it reaches the value $24 \%$ with $\mathrm{ROB}=0.897$, which matches 26 out of 29 scenarios. $\mathrm{P} 1+\mathrm{P} 2$ period combination shows decrease $7 \%$ with $\mathrm{ROB}=0.759$, which matches $22 / 29$ scenarios. In the period combination $\mathrm{P} 1+\mathrm{P} 2+\mathrm{P} 3$ the outflow decreases of $19.6 \%$ with $\mathrm{ROB}=0.862$, which matches $25 / 29$ climate change scenarios.

\section{Conclusions}

The results show the falling trend of river flows and reservoir outflows. Resulting river flow recession in the catchment correspond to the emission scenarios according to their anthropogenic influence on the climate change magnitude. The pessimistic A2 scenario shows the highest flow decrease, on the other hand, B1 scenario river flow decreases are the lowest. The reservoir outflow results indicate that for the input $\mathrm{R}_{\mathrm{T}}$ and $\mathrm{V}_{\mathrm{Z} \text {,max }}$, the total outflow will drop. However, taking into account uncertainties of the climate change, which was described by climatic and hydrological data ensemble, the final outflow values are quite robust, and they should be satisfactory even under the future climate change conditions.

If we look beyond the detailed results, which are interesting rather for reservoir and river basin managers, the following main conclusions of this paper are: The governing equations of lumped water balance model were successfully tested in the Central Europe hydrology conditions. Compared to the original use territory conditions, these are specific by large temporal and spatial rainfall variability and the greater variability of the flows in the catchment. If the model is set up conveniently, good calibration and validation dataset ratio is found, and appropriate optimization method is used, the water balance model equations are applicable to other catchments with different climatic and hydrological conditions. In the case study described in this paper, suitable number of calibration coefficients was 37 and the calibration/validation dataset ratio was 40/13 years. The paper also showed a convenient link between the hydrological model and the reservoir simulation model with climatic system uncertainties taken into account. Also the method of expressing the uncertainties of the hydrological reliability with the resulting robustness connection has been found. Currently, the hydrological model is programmed as an integrated algorithm and it is universally applicable to all types of the catchments in the Czech Republic and possibly Central Europe. Present algorithm version uses a new coefficients optimization based on the modified differential evolution method. The reservoir simulation model can be also described as universal algorithm, which might be adapted for any reservoir under hydrological stress of climate change condition if the inflows data and the reservoir area and volume curves are available. The models could also be used for future application of integrated sediment management, which is going to be a key issue in a sense of sustainable water resources management and drought management strategies. 


\section{Acknowledgement}

This paper was supported by the specific research project FAST-S-18-5341 "Climate Change Uncertainty Propagation in the Hydrological and Water Management Applications".

\section{References}

Devia, G., Ganasri, B., \& Dwarakish, G. (2015). A Review on Hydrological Models. Aquatic Procedia (p. doi.org/10.1016/j.aqpro.2015.02.126). Elsevier D.V.

Hashimoto, T., Stedinder, J., \& Loucks, D. (1982). Reliability, Resiliency, and Vulnerability Criteria For Water Resource System Performance Evaluation. Water Resources Research.

Kašpárek, L., Peláková, M., \& Boersema, M. (2005). Estimation of Reservoirs Capacities for Compensation of River Flows Decrease Due to Climate Change. Retrieved from EAGRI.cz: http://eagri.cz/public/web/file/37101/VUV_klim_zmen_1_.pdf

Klemes, V. (1967). Reliability estimates for a storage reservoir with seasonal input. Journal of Hydrology, pp. 198-216.

Marton, D., Paseka, S., \& Knoppová, K. (2016). Reservoir Storage Capacity Aanalysis Under Conditions of Uncertainty and Climate Change. CCWI (2016 b) Conference Proceeding. Amsterdam.

Marton, D., Starý, M., \& Menšík, P. (2015). Analysis of the influence of input data uncertainties on determining the reliability of reservoir storage capacity. Journal of Hydrology and Hydromechanic, pp. 287-294.

Ministry of Agriculture of the Czech Republic. (2018). Agriculture Adaptaion on Climate Change in the Czech Republic: summary. Retrieved from EAGRI.cz: http://eagri.cz/public/web/file/552908/publikace_Adaptace_zemedelstvi_final.pdf

Paton, F., Maier, H., \& Dandy, G. (2014). Including adaptation and mitigation responses to climate change in a multiobjective evolutionary algorithm framework for urban water supply systems incorporating GHG emissions. Water Resources Research, p. doi:10.1002/2013WR015195.

Racsko, P., Szeidl, L., \& Semenov, M. (1991). A serial approach to local stochastic weather models. Ecological Modelling, 1-2, pp. 27-41.

Roach, T., Kapelan, Z., Ledbetter, R., \& Ledbetter, M. (2016). A Comparison Of Robust Optimization and Info-Gap Methods for Water Resource Management Under Deep Uncertainty. Journal of Water Resources Planning and Management.

Semenov, M., Pilkington-Bennet, S., \& Calanca, P. (2013). Validation of ELPIS 1980-2010 baseline scenarios using the European Climate Assessment observed dataset. Climate Research, pp. $1-9$.

Scharffenberg, W., \& Fleming, M. (2008). Hydrologic Modeling System (HEC-HMS) Applications Guide: Version 3.1.0. Davis, CA: Hydrologic Engineering Center.

Vizina, A., Horáček, S., \& Hanel, M. (2015). Recent developments of the BILAN model. Water Management Technical and Economical Information Journal, 4-5, pp. 7-10.

Wang, G., Zhang, J., Xuan, Y., Liu, J., Jin, J., Bao, Z., et al. (2013). Simulating the impact of climate change on runoff in a typical river catchment of the Loess Plateau, China. Journal of Hydrometeorology, pp. https://doi.org/10.1175/JHM-D-12-081.1.

Zahradníček, P., Trnka, M., Brázdil, R., Možný , M., Štěpánek, P., Hlavinka, P., et al. (2014, December 10). The extreme drought episode of August 2011-May 2012 in the Czech Republic. The International Journal of Climatology, p. https://rmets.onlinelibrary.wiley.com/doi/abs/10.1002/joc.4211. 